\title{
Time-resolved spectroscopy of photo-induced electron transfer in dinuclear and tetranuclear Fe/Co Prussian Blue Analogues
}

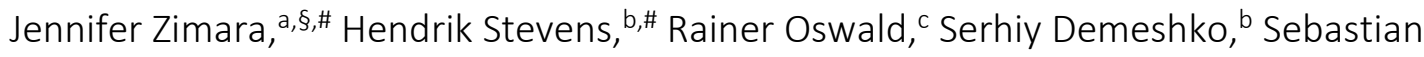 \\ Dechert, ${ }^{b}$ Ricardo A. Mata, ${ }^{c, *}$ Franc Meyer, ${ }^{b, d, *}$ and Dirk Schwarzer ${ }^{a, *}$ \\ a Max-Planck-Institute for Biophysical Chemistry, Am Fassberg 11, 37077 Göttingen, Germany \\ b University of Göttingen, Institute for Inorganic Chemistry, Tammannstraße 4, D-37077 Göttingen, Germany \\ c University of Göttingen, Institute for Physical Chemistry, Tammannstraße 6, D-37077 Göttingen, Germany \\ d International Center for Advanced Studies of Energy Conversion (ICASEC), Tammannstraße 6, D-37077 Göttingen, Germany \\ $\S$ Current address: Laser Laboratory Göttingen (LLG), Hans-Adolf-Krebs-Weg 1, 37077 Göttingen, Germany \\ \# these authors contributed equally to the work
}

The dynamics of photo-driven charge transfer-induced spin transition (CTIST) in two Fe/Co Prussian Blue Analogues (PBAs) is revealed by femtosecond IR and UV/vis pump-probe spectroscopy. Depending on temperature the known tetranuclear squaretype complex $\left[\mathrm{CO}_{2} \mathrm{Fe}_{2}(\mathrm{CN})_{6}\left(\mathrm{tp}^{*}\right)_{2}\left(4,4^{\prime} \text {-dtbbpy }\right)_{4}\right]\left(\mathrm{PF}_{6}\right)_{2}(\mathbf{1})$ exists in two electronic states. In acetonitrile solution at $<240 \mathrm{~K}$ the low temperature (LT) phase is prevalent consisting of low-spin Fe(II) and low-spin Co(III), [Fe" $\left.{ }_{\mathrm{LS}} \mathrm{CO} \mathrm{III}_{\mathrm{LS}}\right]_{2}$. Temperature rise causes thermally induced CTIST towards the high temperature (HT) phase consisting of low-spin Fe(III) and high-spin Co(II), [Fe ${ }^{I I I S-}$ $\mathrm{CO}^{\prime \prime} \mathrm{HS}_{2}$, being prevalent at $>300 \mathrm{~K}$. Photo-excitation into the intervalence charge transfer (IVCT) band of the LT phase at 800 $\mathrm{nm}$ induces electron transfer in one Fe-Co edge of PBA 1 and produces a [Fe"l' ${ }_{\mathrm{LS}} \mathrm{Co}_{\mathrm{LS}}{ }_{\mathrm{LS}}$ ] intermediate which by spin crossover (SCO) is stabilized within $400 \mathrm{fs}$ to a long-lived (>1 ns) [Fe"l' ${ }_{\mathrm{LS} C O}{ }^{\prime \prime} \mathrm{HS}$ ]. In contrast, IVCT excitation of the HT phase at $400 \mathrm{~nm}$ generates a $\left[\mathrm{Fe}^{\prime \prime}{ }_{\mathrm{LS}} \mathrm{CO}{ }^{\prime \prime}{ }_{\mathrm{HS}}\right]$ species with a lifetime of $3.6 \mathrm{ps}$. Subsequent back-electron transfer populates the vibrationally hot ground state, which thermalizes within $8 \mathrm{ps}$. The newly synthesized dinuclear PBA, $\left[\mathrm{CoFe}(\mathrm{CN})_{3}\left(\mathrm{tp}^{*}\right)\left(\mathrm{pz}_{4}{ }_{4} \mathrm{Lut}\right)\right] \mathrm{ClO}_{4}(2)$, provides a benchmark of the $\mathrm{HT}$ phase of 1 , i.e. [ $\mathrm{Fe}^{\mathrm{III}}{ }_{\mathrm{LS}} \mathrm{CO} \mathrm{O}_{\mathrm{HS}}$ ], as verified by variable temperature magnetic susceptibility measurements and ${ }^{57} \mathrm{Fe}$ Mößbauer spectroscopy. The photo-induced charge transfer dynamics of PBA 2 indeed is almost identical to that of the HT phase of PBA 1 with a lifetime of the excited [ $\mathrm{Fe}^{\prime \prime}{ }_{\mathrm{LS}} \mathrm{CO} \mathrm{OI}^{\mathrm{IH}}$ ] species of $3.8 \mathrm{ps}$.

\section{Introduction}

Fe/Co Prussian Blue analogues (PBA) are known for their switchable spin and redox states, making them particularly interesting for information processing at a molecular level and nanoscale electronic components. Apart from data storage, ${ }^{1}$ potential fields of application include optical displays, ${ }^{2}$ holography, ${ }^{3}$ and sensor technology. ${ }^{2,4}$ The spin state of PBAs can be switched by external stimuli such as temperature, pressure, electromagnetic radiation, redox potential or magnetic fields. $5,6 \mathrm{~A}$ particularly attractive feature of some $\mathrm{Fe} / \mathrm{Co} \mathrm{PBA}$ compounds is their photomagnetic behaviour where intramolecular metal-to-metal electron transfer is coupled to a spin crossover (SCO) process at the cobalt ion, viz., a cyanide-bridged diamagnetic $\left(\mathrm{LS}-\mathrm{Fe}{ }^{\prime \prime}\right)(\mu-\mathrm{CN})\left(\mathrm{LS}-\mathrm{CO}^{\prime \prime \prime}\right)$ entity transforms into a paramagnetic (LS-Fe"II) $(\mu-C N)(H S-C O ")$ state (see Scheme 1; LS = low spin, HS = high-spin). ${ }^{7-9}$ This phenomenon has been termed charge transfer induced spin transitions (CTIST) ${ }^{10}$ or electron-transfer-coupled spin transition (ETCST). ${ }^{11}$

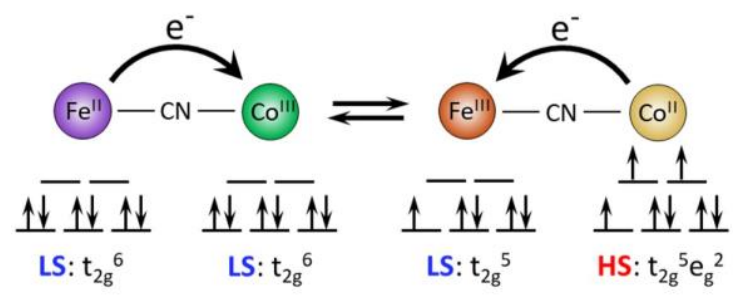

Scheme 1. Conversion between the paramagnetic high-spin (right) and the diamagnetic low-spin (left) state in a Fe/Co PBA entity caused by CTIST using external stimuli.
The first photo-induced CTIST resulting from direct intervalence charge transfer (IVCT) excitation was already reported in 1996 by Hashimoto et al.. ${ }^{12}$ In 2004 Dunbar et al. demonstrated photo- and reversible thermally induced CTIST in a pentanuclear $\left[\mathrm{Fe}_{2} \mathrm{CO}_{3}\right]$ PBA. ${ }^{13,14}$ Shortly after that thermal- and photo-induced CTIST was also shown for octanuclear (cube-type) and tetranuclear (square-type) $\mathrm{Fe} / \mathrm{Co}$ PBAs. ${ }^{15-17}$ Subsequently, a wide variety of multinuclear molecular PBAs with CTIST character was synthesized. ${ }^{18-29}$ Apart from larger PBA units and network systems, ${ }^{30}$ the field also evolved towards the smallest unit cell, the dinuclear [FeCo] PBA. ${ }^{31,32}$ The first dinuclear PBA presented by Bernhardt et al., ${ }^{33-35}$ however, showed neither thermal- nor photo-induced CTIST. First indication of a photo-induced CTIST in a dinuclear PBA was demonstrated in 2005 by Macpherson et al. ${ }^{36}$ using ns- and fsUV/vis-pump-UV/vis-probe spectroscopy. In that case, IVCT excitation of a [(LS-Fe')(LS-Co'II)] ground state with fspulses at room temperature leads to a [(LS-Fe $\left.{ }^{\prime \prime \prime}\right)\left(\right.$ LS-Co $\left.\left.{ }^{\prime \prime}\right)\right]$ excited state, which within a picosecond relaxes back to the ground state involving back-electron transfer. Spincrossover to the energetically favourable [(LS-Fe $\left.{ }^{\text {III }}\right)$ (HSCo"l)] was considered unimportant because too slow compared to the back-electron transfer rate. At $11 \mathrm{~K}$, however, and excitation with ns pulses a long-lived excited state (>>1ns) was observed and attributed to the [(LS-Fe ${ }^{\text {III })(H S-~}$ Co"l)] spin-crossover state. It was supposed that this state is accumulated within the ns-pulse where the molecules undergo many excitation-relaxation cycles and each time a small fraction branches into the long-lived spin crossover state $\left[\left(\mathrm{LS}-\mathrm{Fe}^{\prime \prime \prime}\right)\left(\mathrm{HS}-\mathrm{CO}^{\prime \prime}\right)\right]$. In more recent years, the local 
electronic structure changes upon switching have been evidenced by element-specific K- and L-edge X-ray absorption spectroscopy (XAS) and X-ray magnetic circular dichroism (XMCD) experiments for a dinuclear Fe/Co PBA, ${ }^{37}$ and by L-edge XAS and XMCD for a $\mathrm{Fe}_{4} \mathrm{CO}_{4}$ cube-type PBA. ${ }^{38}$ Occurrence of a phase transition in a $\mathrm{Fe}_{2} \mathrm{CO}_{2}$ square induced by $X$-ray irradiation during XAS measurements has also been reported. ${ }^{39}$ However, spectroscopic studies with high time resolution that track the ultrafast elementary steps of the CTIST process have remained scarce so far.

In this work we performed femtosecond pump-probe measurements in the UV/vis and midIR spectral region to elucidate the dynamics of photo-induced CTIST processes in two Fe/Co PBAs. The first one is the well-known tetranuclear $\quad\left[\mathrm{CO}_{2} \mathrm{Fe}_{2}(\mathrm{CN})_{6}\left(\mathrm{tp}^{*}\right)_{2}\left(4,4^{\prime}-\mathrm{dtbbpy}\right)_{4}\right]\left(\mathrm{PF}_{6}\right)_{2} \cdot 2 \mathrm{MeOH}$ (1.2MeOH) presented by Oshio et al. ${ }^{17,40}$ which was shown to undergo thermal- and photo-induced CTIST. We regard PBA 1 as an ideal benchmark system because it allows for investigating both, the $\left[\left(\mathrm{LS}-\mathrm{Fe}{ }^{\prime \prime}\right)_{2}\left(\mathrm{LS}-\mathrm{Co} \mathrm{O}^{\prime \prime \prime}\right)_{2}\right]$ state (the low temperature, LT phase) and the $\left[\left(\mathrm{LS}-\mathrm{Fe}^{\prime \prime \prime \prime}\right)_{2}\left(\mathrm{HS}-\mathrm{CO}^{\prime \prime}\right)_{2}\right]$ state (the high temperature, HT phase) due to its high CTIST transition temperature of $T_{1 / 2}=275 \mathrm{~K}$. The second compound is the newly synthesized dinuclear $\left[\mathrm{CoFe}(\mathrm{CN})_{3}\left(\mathrm{tp}^{*}\right)\left(\mathrm{pz}^{*}{ }_{4} \mathrm{Lut}\right)\right] \mathrm{ClO}_{4}$ (2) with $\mathrm{pz}_{4}{ }^{*} \mathrm{Lut}^{41}$ as the capping ligand at the Co site. Dinuclear PBAs have been considered as the ultimate miniaturization, ${ }^{32}$ which allows to study the inherent processes in an individual [FeCo] entity; note that square PBAs such 1 formally contain two such [FeCo] entities, and single photon excitation may possibly induce IVCT in only one of them. For this study PBA 2 was developed to provide a benchmark system representing the $\mathrm{HT}$ phase of a [FeCo] subunit of 1 . X-ray crystallography, ${ }^{57} \mathrm{Fe}-\mathrm{Mößb} b a u e r$ spectroscopy and SQUID measurements clearly characterize PBA 2 as a [(LS-Fe"II)(HS-Co")] system, viz. similar to the HT phase of PBA 1.

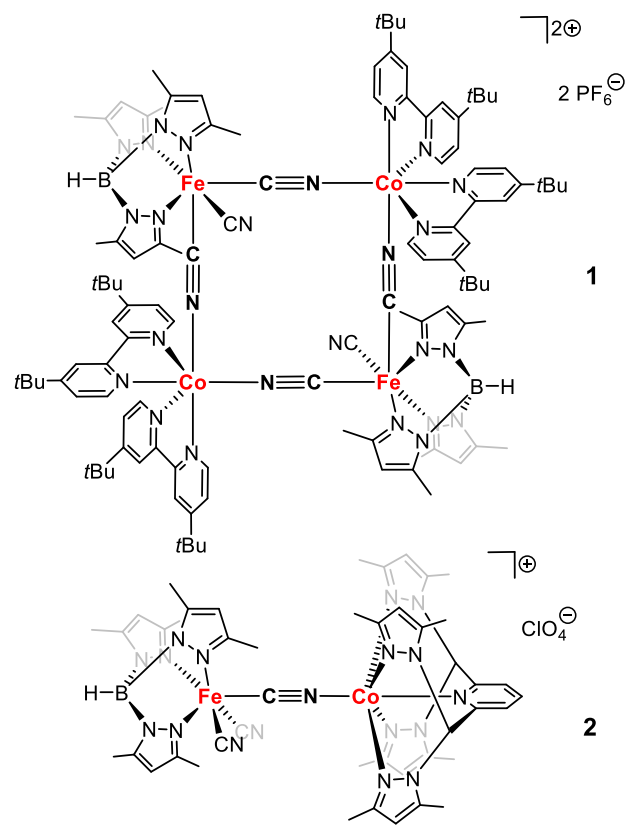

Figure 1. Schematic drawing of compounds $\mathbf{1}^{28}$ and 2 studied in this work.
Our time-resolved experiments indeed show that photoexcitation into the IVCT band of the LT phase of PBA 1 induces electron transfer in one [FeCo] subunit, and by fast spin-crossover, conversion to a long-lived [(LS-Fe")(LSCo'II)(LS-Fe"II)(HS-Co'I)] species. In contrast, photo-induced IVCT in the HT phase produces a short-lived intermediate, which relaxes by back-electron transfer within $3.8 \mathrm{ps}$. The photophysics of PBA 2 indeed is almost identical to that of the HT phase of PBA 1.

\section{Results and discussion}

\section{Synthesis and characterization of dinuclear PBA 2}

To simplify possible excitation pathways, the dinuclear $\mathrm{Co} / \mathrm{Fe} \mathrm{PBA}(2)$ was synthesized by the equimolar reaction of $\mathrm{Co}\left(\mathrm{ClO}_{4}\right)_{2}$ and $\mathrm{pz}^{*}{ }_{4} \mathrm{Lut}$ with $\mathrm{Bu} \mathrm{u}_{4} \mathrm{~N}\left[\mathrm{tp} * \mathrm{Fe}(\mathrm{CN})_{3}\right]$ similar to literature procedures for related complexes. ${ }^{32}$ Suitable crystals for X-ray diffraction analysis were obtained by slow diffusion of diethyl ether into a methanolic solution of the crude product. PBA (2) crystallizes in the triclinic space group $P-1$.

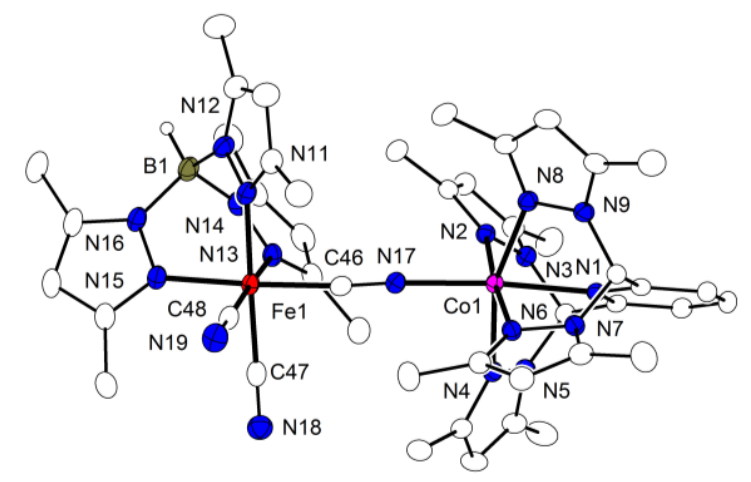

Figure 2. Plot ( $50 \%$ probability thermal ellipsoids) of the cationic part of PBA (2) (most hydrogen atoms omitted for clarity).

The molecular structure of PBA (2) in solid state (Figure 2) shows the Co ion in a distorted octahedral coordination environment, the distortion being imposed by the constraints of the pentadentate capping ligand (with angles N1-Co1-N2/4/6/8 in the range $\left.80.16(5)-89.59(5)^{\circ}\right)$. In contrast, the octahedral coordination environment of the Fe ion is much less distorted. By comparison with the HT phase of PBA 1 the average bond lengths around Co (2.0510(15)-2.2349(15) Å) and Fe (1.9128(18)-2.0054(15) $\AA)$ in PBA 2 indicate a [(LS-Fe'II)(HS-Co'l)] configuration. In PBA 1 the CTIST below $275 \mathrm{~K}$ to the [(LS-Fe"I)(LS-Co'III)] state results in a shortening of the average coordination bonds around the Co ion to 1.892(7)-1.944(6) A. ${ }^{17}$ Upon cooling to $133 \mathrm{~K}$ this reduction in bond lengths is not observed for 2 , which means that there is no thermally induced electron transfer above $133 \mathrm{~K}$. The absence of any CTIST in 2 can likely be attributed to the long bonds between the Co centre and the $\{$ N5 $\}$ capping ligand (up to $2.235 \AA$ ) imposed by the chelate constraints which disfavour the transition to LS-Co"l' with considerably shorter bond lengths. 


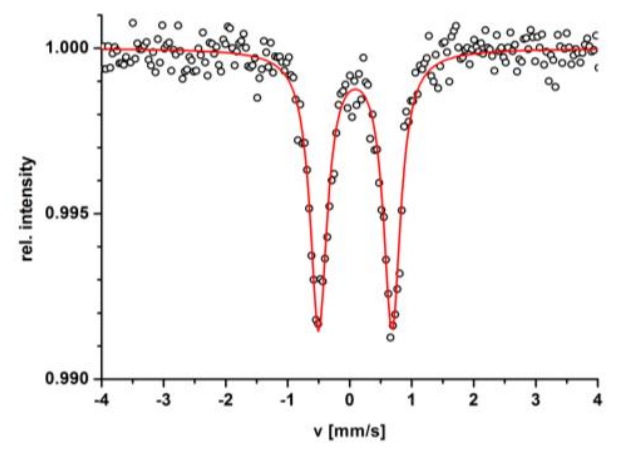

Figure $3 .{ }^{57} \mathrm{Fe}-\mathrm{Mößbauer}$ spectra of PBA (2) at $80 \mathrm{~K}$. The solid red line is the Lorentzian curve fit yielding the parameters $\delta=0.09$ and $\Delta \mathrm{E}_{\mathrm{Q}}=1.18 \mathrm{mms}^{-1}$.

To confirm the electronic structure of PBA 2 in the solid

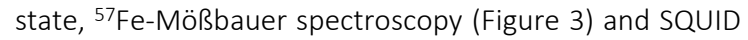
measurements (Figure 4) were performed. The zero-field ${ }^{57} \mathrm{Fe}-\mathrm{Mößbauer}$ spectrum of solid 2 recorded at $80 \mathrm{~K}$ shows a quadrupole doublet with isomer shift $\delta=0.09$ and quadrupole splitting $\Delta E_{\mathrm{Q}}=1.18 \mathrm{mms}^{-1}$ which is characteristic for a LS-Felll state. These results confirm that PBA 2 does not undergo any thermally induced CTIST to [(LS-Fe")(LS-Co'II)] above $80 \mathrm{~K}$. In contrast, the tetranuclear complex 1 at 20 $\mathrm{K}$ shows values of $\delta=0.22$ and $\Delta E_{\mathrm{Q}}=0.43 \mathrm{mms}^{-1}$ in accordance with a LS-Fell situation. ${ }^{17}$

Results of the magnetic measurement of 2 are presented in Figure 4 and show no LS/HS transition in the entire temperature range $2-300 \mathrm{~K}$. At room temperature the $\chi_{\mathrm{M}} T$ value of 2 is $3.7 \mathrm{~cm}^{3} \cdot \mathrm{K} \cdot \mathrm{mol}^{-1}$, representing the sum of the two spin systems LS-Fe'll $(S=1 / 2)$ and HS-Co"l $(S=3 / 2)$. When lowering the temperature $\chi_{\mathrm{M}} T$ gradually decreases and reaches a minimum value of $1.4 \mathrm{~cm}^{3} \cdot \mathrm{K} \cdot \mathrm{mol}^{-1}$ at $2 \mathrm{~K}$, which can be well simulated assuming zero-field splitting of the HS-Coll ion $\left(D=-125 \mathrm{~cm}^{-1}\right)$. The pronounced drop of the $\chi_{\mathrm{M}} T$ value below $15 \mathrm{~K}$ can be attributed to a weak antiferromagnetic interaction between the LS-Fe"lI and HS-Co"I centres through the cyanide bridging ligand with an ex- change coupling constant $J=-1.3 \mathrm{~cm}^{-1}$. Details of the magnetic data analysis are provided in the Supporting Information.

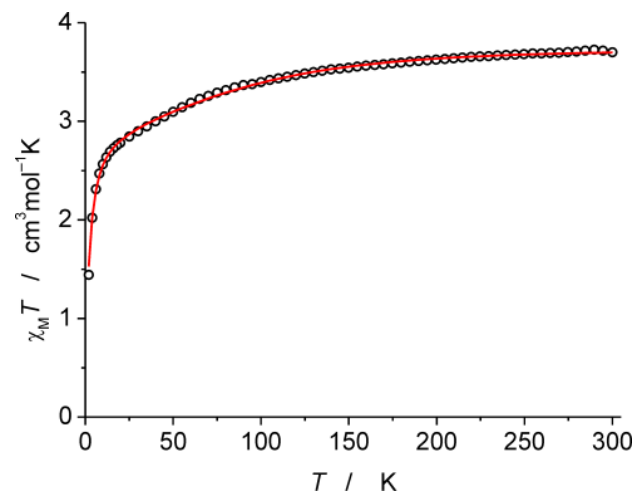

Figure 4. $\chi_{\mathrm{M}} T$ versus $T$ curve of crystalline PBA 2 from 2 to $300 \mathrm{~K}$. Dots are experimental data and the solid red line represents a simulation with the parameters $J=-1.3 \mathrm{~cm}^{-1}, D(C o)=-125 \mathrm{~cm}^{-1}$, $g_{\times}(\mathrm{Co})=g_{\mathrm{y}}(\mathrm{Co})=2.42, g_{\mathrm{z}}(\mathrm{Co})=2.88$ and $\mathrm{g}_{\text {iso }}(\mathrm{Fe})=2.40$ (fixed); see SI for details.

\section{Temperature dependent UV/vis and FTIR spectra}

Tetranuclear PBA 1: Figure 5 shows the temperature-dependent stationary UV/vis (a) and FTIR (b, c) absorption spectra of the tetranuclear PBA 1 in acetonitrile solution. Between $-30^{\circ} \mathrm{C}$ and $+30^{\circ} \mathrm{C}$ both exhibit the transition from the LT [(LS-Fe")(LS-Co'II)] to the HT [(LS-Fe'II)(HS-Co'I)] phase. Consistent with literature data ${ }^{17}$ the UV/vis spectrum of the LT phase is dominated by a broad IVCT band centred at $770 \mathrm{~nm}$ and a more narrow peak at $428 \mathrm{~nm}$. With increasing temperature this spectrum disappears and the absorptions of the HT phase peaking at $460 \mathrm{~nm}$ with a shoulder at around $550 \mathrm{~nm}$ emerges.

Figure $5 \mathrm{~b}$ and $\mathrm{c}$ show the temperature-induced transition from the LT to the HT phase for the CN and the tp* ligands' B-H stretching vibrations of PBA $1, v_{C N}$ and $v_{B H}$, respectively. Their resonance frequencies exhibit a clear dependence on oxidation and spin state of the metal ions. Com-

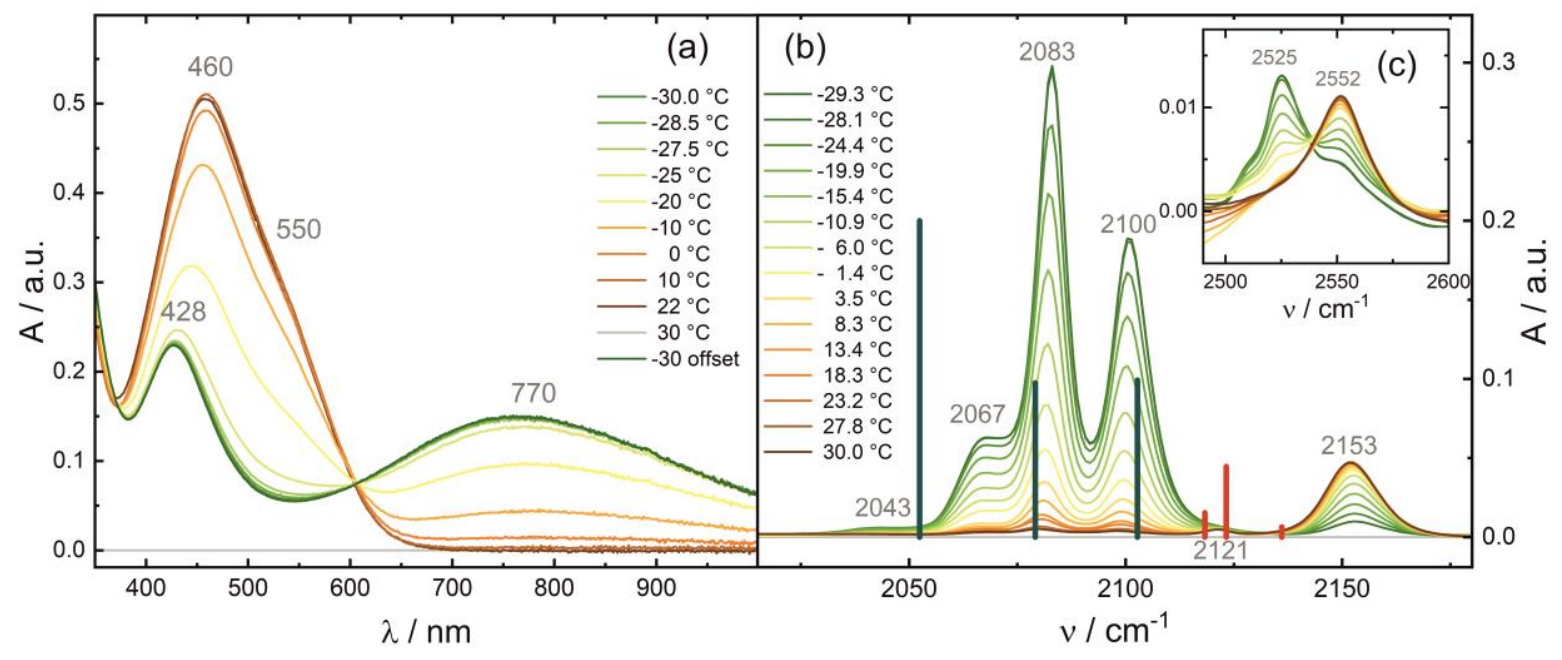

Figure 5. Temperature-dependent UV/vis (a) and FTIR (b, c) absorption spectra of PBA 1 at 0.8 mM in acetonitrile solution. Stick spectra in (b) result from DFT calculations for ${ }^{1}\left[\mathrm{Fe}_{2}{ }^{\prime \prime} \mathrm{LSCO}_{2}{ }^{\text {IIIs }} \mathrm{LS}\right.$ (green) and ${ }^{5}\left[\mathrm{Fe}_{2}{ }^{\prime \prime \prime \prime} \mathrm{LSO}_{2}{ }^{\prime \prime} \mathrm{HS}\right]$ (red). 
pared to the LT phase the vibrational bands of the HT complex show a hypsochromic shift and reduced intensity. Figure $5 \mathrm{c}$ indicates a blue-shift also for the $\mathrm{B}-\mathrm{H}$ stretching mode of the Fe-coordinated tp* ligands when going from the LT to the HT phase.

The isosbestic point at $603 \mathrm{~nm}$ in the UV/vis spectra and the absence of any IR vibrational bands appearing intermediately during the $\mathrm{LT} \rightarrow \mathrm{HT}$ phase transition indicate that charge transfer happens in a cooperative manner, i.e. simultaneously for both [FeCo] subunits and not stepwise. Compared to the solvent butyronitrile $\left(T_{1 / 2}=-46^{\circ} \mathrm{C}\right)$ the transition in acetonitrile appears at higher temperature $\left(T_{1 / 2}=-11 \pm 4^{\circ} \mathrm{C}\right)$ due to distinct complex-solvent interactions. The reaction enthalpy and entropy derived for the transformation from the LT to the HT phase in acetonitrile are $\Delta H=+79 \mathrm{~kJ} / \mathrm{mol}$ and $\Delta S=+299 \mathrm{~J} /(\mathrm{mol} \mathrm{K})$, respectively (see $\mathrm{SI}$ for details), very similar to the values reported for 1 in butyronitrile $\left(\Delta H=+68 \mathrm{~kJ} \cdot \mathrm{mol}^{-1}, \Delta S=+299 \mathrm{~J} \cdot \mathrm{mol}^{-1} \cdot \mathrm{K}\right)$; the large $\Delta S$ was attributed to a substantial contribution from solvent reorganization upon electron transfer. ${ }^{17}$

Dinuclear PBA 2. As PBA 2 exists only in the HT phase (see the SQUID-magnetometry measurements and ${ }^{57} \mathrm{Fe}$ Mößbauer spectrum shown in Figs. 3 and 4, respectively) we present in Figure 6 only its room temperature optical and IR spectra. Comparison with the HT phase of the square PBA 1 shows similar absorption features. The UV/vis absorption spectrum of 2 exhibits a maximum at $448 \mathrm{~nm}$ and a shoulder around $510 \mathrm{~nm}$. In the FTIR spectrum two peaks at 2115 and $2123 \mathrm{~cm}^{-1}$ can be attributed to the symmetric and anti-symmetric stretching vibration of the terminal $\mathrm{CN}$ groups at the Fe site, respectively. The $\mathrm{CN}$ stretching mode of the bridged cyanide is located at $2144 \mathrm{~cm}^{-1}$.

\section{Electronic Structure Calculations}

Both PBAs were modelled computationally in order to provide a solid basis for assigning the nature of the $v_{\mathrm{CN}}$ modes in the linear and transient IR difference spectra. The calculations were carried out with three density functionals: B3LYP, PBEO and BP86. The results discussed in the text were computed at the BP86-D3/def2-SVP level of theory. The latter functional gave the fundamental band positions in best agreement with the experimental measurements; however, all methods gave close agreement in the relative band positions. The full list of results is provided in the SI. Calculations on the dinuclear PBA 2 targeted the potential ground state, ${ }^{5}\left[\left(\mathrm{LS}-\mathrm{Fe}^{\mathrm{III}}\right)\left(\mathrm{HS}-\mathrm{CO}^{\prime \prime}\right)\right]$, and the corresponding excited state ${ }^{5}\left[\left(\mathrm{LS}-\mathrm{Fe}^{\prime \prime}\right)\left(\mathrm{HS}-\mathrm{Co}^{\prime \prime \prime}\right)\right]$; these two states would correspond to the same spin (quintet). Given the high multi-reference character of these configurations and the inherent difficulties of optimizing excited states at the DFT level, fragment calculations were carried out (building fragments from each individual metal ions and the respective ligands) while fixing the partial charge and spin accordingly. The targeted states could only be obtained by also including a triplet state ${ }^{3}\left[\left(\mathrm{LS}-\mathrm{Fe} \mathrm{III}^{\mathrm{II}}\right)\left(\mathrm{HS}-\mathrm{CO} \mathrm{O}^{\prime \prime}\right)\right]$, which would effectively pair the spins of the two metal ions. This is in accordance with the weak antiferromagnetic interaction between the LS-Fe ${ }^{\text {III }}$ and HS-Coll centres observed experimentally (Figure $4 ; J=-1.3 \mathrm{~cm}^{-1}$ ). For the ground state, we obtain a dominant IR band at $2136 \mathrm{~cm}^{-1}$ (symmetric C-N stretches). The $\mathrm{C}-\mathrm{N}$ stretch motions of the bridging and terminal cyanide ligands are again featured in the remaining bands at 2121 and $2125 \mathrm{~cm}^{-1}$, respectively. This analysis is based on the purely harmonic modes. The computed fundamentals for the ground state agree favourably with the experimental spectra (see the violet stick spectrum in Figure 6b). A quintet state was also computed, corresponding to ${ }^{5}\left[\left(\mathrm{LS}^{-} \mathrm{Fe}^{\mathrm{II}}\right)\left(\mathrm{HS}-\mathrm{Co}{ }^{\prime \prime \prime}\right)\right]$ (black stick spectrum in Figure $6 \mathrm{~b}$ ). The strongest absorbing fundamental band now corresponds to an isolated $\mathrm{C}-\mathrm{N}$ stretch motion of the $\mu-C N$ (at $2086 \mathrm{~cm}^{-1}$ ) while the other modes are found to be close to those of the ${ }^{3}\left[\left(\mathrm{LS}-\mathrm{Fe}{ }^{\prime \prime \prime}\right)\left(\mathrm{HS}-\mathrm{Co} \mathrm{O}^{\prime \prime}\right)\right]$ ground state (2123 and $2129 \mathrm{~cm}^{-1}$ ). In order to understand these values, a Natural Population Analysis of both electronic states was carried out. We observe that the charge and electron distribution of the Fe centre is kept largely unaltered, resembling mostly a LS-Fe III ion in both states. The charge, which is shifted to the Co centre upon IVCT, is for the most part drawn from the ligand on the Fe side.

The calculations were also extended to the tetranuclear PBA compound 1. Its ground state is confirmed to be a singlet ${ }^{1}\left[\left(\mathrm{LS}-\mathrm{Fe}^{\prime \prime}\right)_{2}\left(\mathrm{LS}-\mathrm{CO} \mathrm{OII}_{2}\right)_{2}\right.$ with three IR active $\mathrm{CN}$ stretching modes at 2052, 2079 and $2103 \mathrm{~cm}^{-1}$ (green stick spectrum in Figure 5b). Contrary to the previous assignment, all these bands involve both, terminal and bridging cyanide

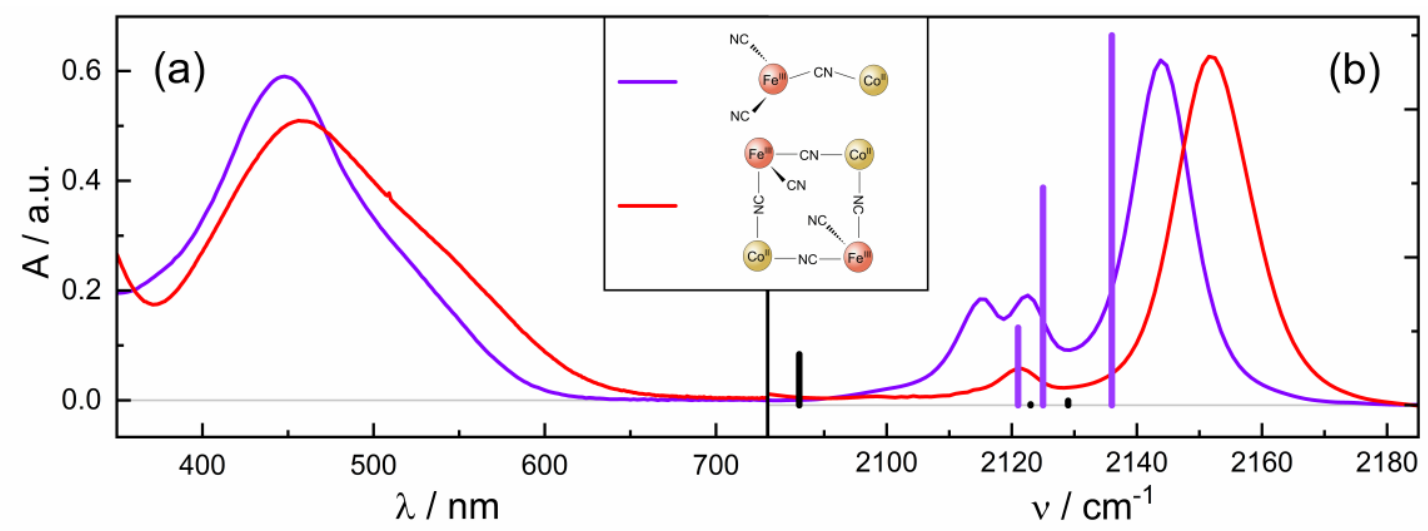

Figure 6. (a) UV/vis absorption and (b) FTIR spectra of the HT phase of the tetranuclear PBA 1 (red) and the dinuclear PBA 2 (violet). Spectra were measured in acetonitrile solution at $22^{\circ} \mathrm{C}$ and concentrations of $0.8 \mathrm{mM}$. Stick spectra in (b) result from DFT calculations for ${ }^{3}\left[\mathrm{Fe}^{\mathrm{III}}\right.$ เSCo $\left.{ }^{\prime \prime} \mathrm{Hs}\right]$ (violet) and ${ }^{5}\left[\mathrm{Fe}^{\prime \prime}\right.$ เSCO ${ }^{\prime \prime \prime}$ Hs] (black). 
ligands, due to pronounced vibrational coupling. The corresponding quintet state of PBA 1 , where coupling within each pair of [(LS-Fe'III)(HS-Co"I)] is antiferromagnetic (triplet) and then the two FeCo pairs are ferromagnetically coupled, exhibits CN stretching modes at 2118, 2123, and $2136 \mathrm{~cm}^{-1}$ (red stick spectrum in Figure $5 b$ ).

\section{Femtosecond pump-probe spectroscopy}

With thorough steady state characterization and band assignment at hand, femtosecond pump-probe spectroscopy was applied to elucidate the photo-induced charge transfer dynamics in the two PBAs. The thermally induced CTIST for square PBA 1 enabled an examination of both its $\mathrm{HT}$ and $\mathrm{LT}$ phases at $-30^{\circ} \mathrm{C}$ and $+22^{\circ} \mathrm{C}$, respectively, while dinuclear PBA 2 provided a benchmark system for the HT phase of square complex 1.

Tetranuclear PBA 1, LT phase. In Figure 7 transient difference spectra (change in absorption, $\triangle \mathrm{A}$, in units of milli optical density, $\mathrm{mOD}$ ) are presented following excitation of the LT phase of PBA 1 at 775 and $800 \mathrm{~nm}$, respectively. The transients formed in the UV/vis region (Fig. 7a) exhibit positive absorption between 350 and $630 \mathrm{~nm}$ with a maximum at $475 \mathrm{~nm}$, a shoulder at $580 \mathrm{~nm}$, and negative absorption at wavelength $>630 \mathrm{~nm}$. Time traces at 410 and $478 \mathrm{~nm}$ (see the insert in Fig. 7a) reveal initial fast relaxation towards an almost constant absorption of a long-lived photoproduct. Corresponding bi-exponential fits (solid lines) yield time constants of $\tau_{1}=400 \pm 80 \mathrm{fs}$ and $\tau_{2}>1 \mathrm{~ns}$. The spectrum at pump-probe delays $>2$ ps shows similarities to the scaled difference spectrum $\left(A_{L T}-A_{H T}\right)$, cf. the grey line in Figure $7 a$, of the stationary absorption spectra of the LT and HT phases, consistent with an IVCT transition being induced by the pump-pulse. The mismatch between the spectra indicates that photo-excitation induces electron transfer in only one Fe-Co couple of PBA 1 producing

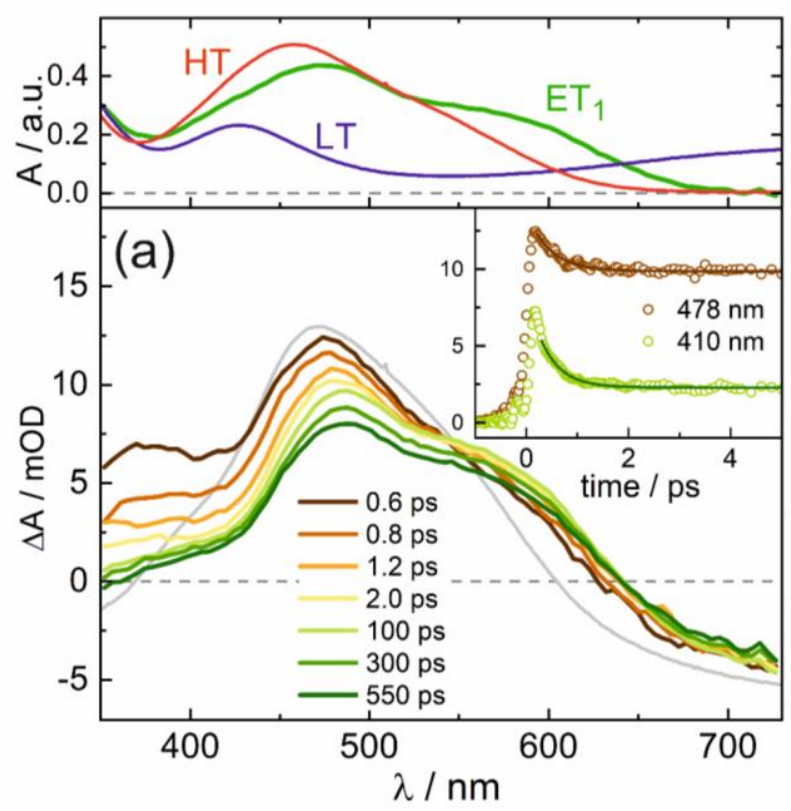

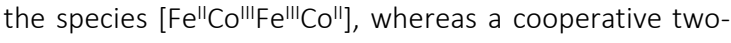
electron transfer in the entire $\mathrm{Fe}_{2} \mathrm{CO}_{2}$ square as it was found for the thermal transition of the LT to the HT phase (Figure 5) does not occur. ${ }^{17}$

The IR transients, Figure $7 \mathrm{~b}$, show bleaching of the $v_{\mathrm{CN}}$ marker bands of the LT phase at 2083 and $2100 \mathrm{~cm}^{-1}$ and formation of a long-lived photoproduct with absorptions centred at 2058 and $2164 \mathrm{~cm}^{-1}$, which basically supports the assignment of a pump pulse-induced IVCT transition. The marked differences in the peak positions to those of the HT phase underpin the existence of an [Fe" $\mathrm{Co}^{\prime \prime \prime} \mathrm{Fe}{ }^{\text {III }} \mathrm{Co}{ }^{\prime \prime}$ ] intermediate formed by one-electron IVCT along one edge of the square. Note, that this intermediate has Fe" $-(\mu-\mathrm{CN})$ Coll and Fe"II-( $\mu-\mathrm{CN})$-Colll edges within the square complex, viz. moieties which do not exist in either the LT or the HT phase. Similar to the UV/vis region the IR transients clearly reveal dynamics on a sub-picosecond timescale. This becomes apparent in an initial amplitude modulation of the $2058 \mathrm{~cm}^{-1}$ band and a $14 \mathrm{~cm}^{-1}$ blue shift of the emerging $2164 \mathrm{~cm}^{-1}$ mode (see insert of Figure 7b). Both occur in a time range consistent with the fast time constant of $\tau_{1}=$ $400 \pm 80$ fs observed for the UV/vis transients (Figure 7a).

Previous low temperature photomagnetic studies on PBA 1 in butyronitrile have shown ${ }^{17}$ that $808 \mathrm{~nm}$ light irradiation of the LT phase at $5 \mathrm{~K}$ induces the Fe"l $\rightarrow$ Coll IVCT accompanied by spin crossover to a [(LS-Fe'III $\left.)_{2}\left(\mathrm{HS}-\mathrm{CO}^{\prime \prime}\right)_{2}\right]$ state. At $5 \mathrm{~K}$ this state is metastable, and only after heating to $80 \mathrm{~K}$ it relaxes back to the thermodynamically more stable LT phase. The data of Figure 7 suggest that at elevated temperatures $\left(-30^{\circ} \mathrm{C}\right)$ individual steps of this reaction cycle can be temporally resolved by their UV/Vis and IR spectral signatures. Starting from the singlet ground state and considering only one $[\mathrm{FeCo}]$ pair, viz. one edge of the square complex (see Scheme 2), photo-induced IVCT of the LT phase produces initially a singlet species ${ }^{1}\left[\mathrm{Fe}^{\mathrm{III}}{ }_{\mathrm{LS}} \mathrm{Co} \mathrm{O}_{\mathrm{LS}}\right.$ ],

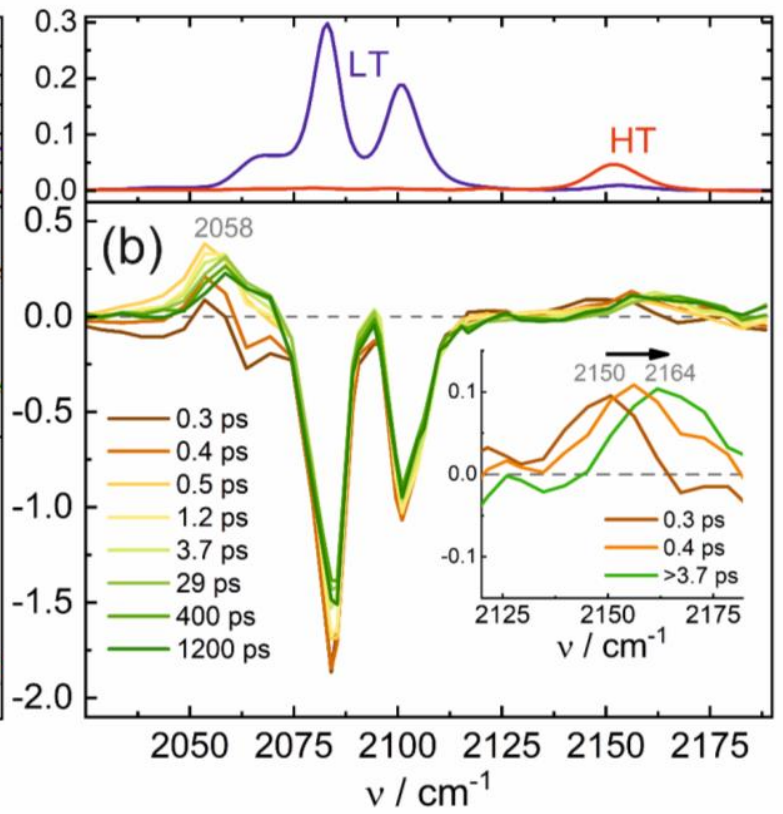

Figure 7. Pump pulse-induced UV/vis (a) and IR (b) transient difference spectra of the LT phase of PBA 1 at - $30^{\circ} \mathrm{C}$ in acetonitrile at pump-probe delays as indicated (pump wavelength: 775 and $800 \mathrm{~nm}$, respectively). Upper panels show corresponding stationary absorption spectra of the $\mathrm{HT}\left(+30^{\circ} \mathrm{C}\right)$ and $\mathbf{L T}$ phase $\left(-30^{\circ} \mathrm{C}\right)$, and in $(\mathrm{a})$ the calculated spectrum of the one-electron transfer product [Fe" ${ }_{\mathrm{LS}} \mathrm{CO}{ }^{\prime \prime \prime}{ }_{\mathrm{LS}} \mathrm{Fe} \mathrm{I}^{\mathrm{II}} \mathrm{LS} \mathrm{CO} \mathrm{O}_{\mathrm{HS}}$ ] (green line). The gray line in $(a)$ is a difference spectrum $\left(A_{L T}-A_{H T}\right)$ calculated from the stationary spectra; the inset in (a) shows time traces for selected probe wavelengths (open symbols) with bi-exponential fits (solid lines) yielding time constants of $\tau_{1}=400 \pm 80 \mathrm{fs}$ and $\tau_{2}>1 \mathrm{~ns}$. The inset in (b) enlarges the $2120-2180 \mathrm{~cm}^{-1}$ spectral range to visualize a sub-picosecond blue shift of this $v_{\mathrm{CN}}$ band. 
which due to weak intramolecular antiferromagnetic coupling coexists with a triplet, ${ }^{3}\left[\mathrm{Fe}^{\mathrm{III}} \mathrm{LS} \mathrm{CO}{ }_{\mathrm{LS}} \mathrm{I}\right]$. If the coupling is weak both species are hard to distinguish because their spectra will be very similar. Therefore, we attribute the fast kinetic component associated with $\tau_{1}=400 \pm 80$ fs to the spin crossover towards the long-lived $\left(\tau_{2}>1 \mathrm{~ns}\right)$ ${ }_{3,5}\left[\mathrm{Fe}^{\mathrm{III}}{ }_{\mathrm{LS}} \mathrm{CO}{ } \mathrm{HS}_{\mathrm{HS}}\right]$ intermediate (again, triplet and quintet forms coexist owing to weak antiferromagnetic coupling of the two metal centers). In the following, we denote this metastable tetranuclear [ $\mathrm{Fe}^{\prime \prime}{ }_{\mathrm{LS}} \mathrm{CO}{ }{ }^{\prime \prime \prime}{ }_{\mathrm{LS}} \mathrm{Fe}{ }^{\prime \prime \prime}{ }_{\mathrm{LS}} \mathrm{CO}{ }{ }_{\mathrm{HS}}$ ] product by $\mathrm{ET}_{1}$.

Interestingly, upon continuous $808 \mathrm{~nm}$ radiation the low temperature photomagnetic studies of 1 reported in literature showed saturation of the $\chi_{m} T$ values at $3.25 \mathrm{emu}$ $\mathrm{mol}^{-1} \mathrm{~K}$, which is almost exactly half the value found for the HT phase. ${ }^{17}$ The authors attributed this to insufficient light-penetration depth of the sample. An alternative explanation based on the present results is that in $\mathrm{ET}_{1}$ produced after one-electron transfer at one edge of the

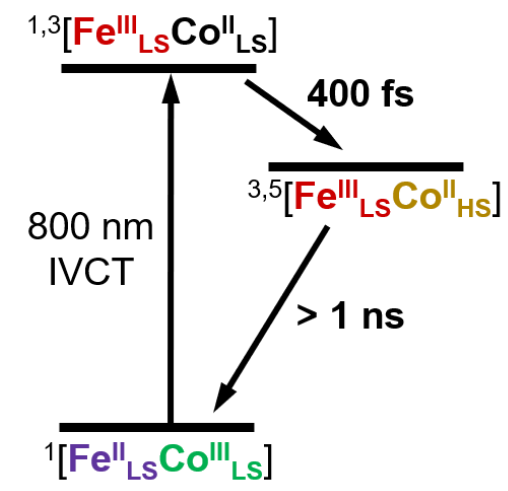

Scheme 2. Light-induced dynamics in one Fe-Co pair of the LT phase of square PBA 1. IVCT excitation is followed by spin-crossover within $400 \mathrm{fs}$ to a long-lived ${ }^{3,5}\left[\mathrm{Fe}^{\mathrm{II}} \mathrm{LSCO}^{\prime \prime} \mathrm{Hs}\right]$ state. Same color code as in Scheme 1

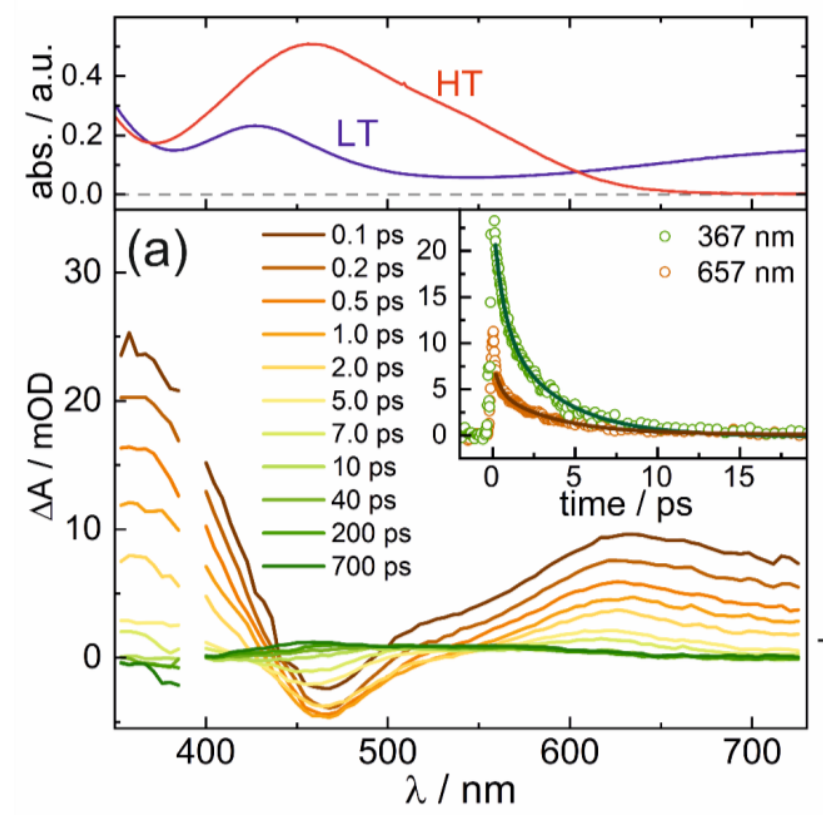

square complex, the Fe"l $\rightarrow$ Coll' IVCT transition for the remaining Fe" ${ }_{L S} \mathrm{CO}^{\prime \prime \prime} \mathrm{LS}$ couple is shifted to higher energies compared to the LT phase and is not accessible by $808 \mathrm{~nm}$ light anymore. If this is the case, the UV/vis spectrum of $\mathrm{ET}_{1}$ can be calculated from the sum of the $550 \mathrm{ps}$ transient in Figure $6 a$ and the absorption spectrum of the LT phase, $\mathrm{A}_{\mathrm{ET} 1}=\Delta \mathrm{A}_{550}+a_{1} \cdot \mathrm{A}_{\mathrm{LT}}$, by choosing the scaling factor $a_{1}$ such that for $\lambda>700 \mathrm{~nm}$ the $\mathrm{ET}_{1}$ absorption converges to zero. The resulting spectrum is plotted as a green line in the upper panel of Figure $7 \mathrm{a}$ and consists of two overlapping bands with maxima at 475 and $600 \mathrm{~nm}$. The former may be assigned to the $\mathrm{Co}{ }^{\prime \prime} \rightarrow \mathrm{Fe}^{\prime \prime \prime}$, the latter to the $\mathrm{Fe}^{\prime \prime} \rightarrow \mathrm{Co}^{\prime \prime \prime}$ IVCT band of [Fe" $\left.{ }_{L S} \mathrm{CO}^{\prime \prime \prime}{ }_{L S} \mathrm{Fe}^{\prime \prime \prime \prime}{ }_{L S} \mathrm{CO}^{\prime \prime}{ }_{\mathrm{HS}}\right]$.

$800 \mathrm{~nm}$ photo-excitation of the LT phase corresponds to an energy input of $150 \mathrm{~kJ} / \mathrm{mol}$. The enthalpy for the thermal reaction $\mathrm{LT} \rightarrow \mathrm{HT}$, on the other hand, is only 79 $\mathrm{kJ} \cdot \mathrm{mol}^{-1}$ (see section 2.2). This raises the question why the photo-induced one-electron transfer of the LT phase does not involve a second (cooperative) CT step towards the HT phase. The reason behind this is probably that after oneelectron transfer any excess energy in the $\mathrm{ET}_{1}$ state is transferred to the surrounding solvent within tens of picoseconds. In this scenario the second CT step is too slow to compete with this vibrational cooling process.

Tetranuclear PBA 1, HT phase. Time-resolved experiments for the HT phase of PBA 1 in acetonitrile were performed at $+22^{\circ} \mathrm{C}$. UV/vis transient spectra (Figure 8 a) were generated using a pump wavelength of $388 \mathrm{~nm}$. They show ground state bleaching superimposed by a broadband excited state absorption producing maxima at $370 \mathrm{~nm}$ and $640 \mathrm{~nm}$. Contrary to the excited states originating from the LT phase, these features are only short-lived as illustrated in the insert of Figure 8a. A minor residual absorption that remains constant over $>1 \mathrm{~ns}$ is attributed to $\sim 3 \%$ of the LT phase being present in acetonitrile solution at

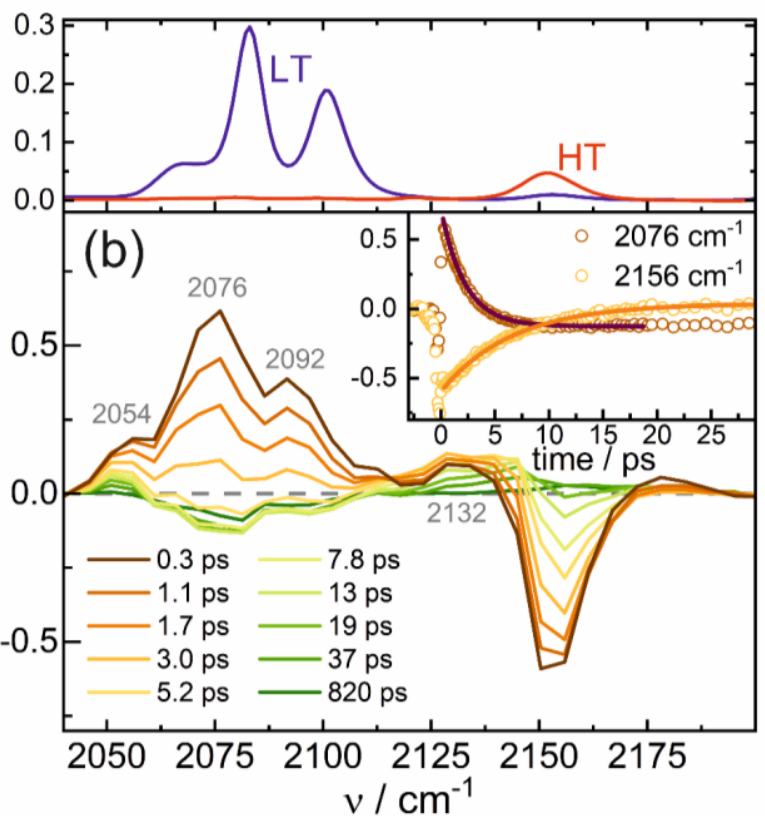

Figure 8. Pump pulse-induced UV/vis (a) and IR (b) transient difference spectra of the HT phase of PBA 1 at $+22^{\circ} \mathrm{C}$ in acetonitrile at pump-probe delays as indicated (pump wavelength: 388 and $400 \mathrm{~nm}$, respectively). The inset shows time traces for selected probe wavelengths/wavenumbers (open symbols) with exponential fits (solid lines). In the upper panels stationary absorption spectra of the $\mathrm{HT}$ phase $\left(+30^{\circ} \mathrm{C}\right)$ and the LT phase $\left(-30^{\circ} \mathrm{C}\right)$ are shown. 
$+22^{\circ} \mathrm{C}$, which is thus excited with $385 \mathrm{~nm}$ light as well. Due to its different absorption spectrum and kinetics, it is easily distinguished from the contribution of the HT phase. The time traces at 367 and $657 \mathrm{~nm}$ both were satisfactorily fitted bi-exponentially with time constants of $500 \pm 200 \mathrm{fs}$ and $3.6 \pm 0.5 \mathrm{ps}$ (solid lines in the insert of Figure 8a). Comparison with the HT and LT phase's stationary absorption spectra (upper panel in Figure 8a) shows that the observed transient spectra are consistent with a light induced $\mathrm{CO}^{\prime \prime} \rightarrow$ Fe'll IVCT transition. A closer analysis, however, reveals that the product spectrum is inconsistent with either of both, the LT phase as well as ET 1 . Hence, excitation of the HT phase obviously leads to a one-electron IVCT intermediate [Fe $\left.{ }^{\prime \prime} \mathrm{Co}{ }^{\prime \prime \prime} \mathrm{Fe} e^{\prime \prime \prime} \mathrm{Co} "\right]$ with an electron configuration different from $\mathrm{ET}_{1}$ and a lifetime limited by back electron transfer within $3.6 \mathrm{ps}$.

Time-resolved IR data for the HT phase of tetranuclear PBA 1 are presented in Figure 8b. Following $400 \mathrm{~nm}$ excitation, the $v_{\mathrm{CN}}$ stretching band of the HT phase at $2153 \mathrm{~cm}^{-1}$ is bleached and new absorption features at 2054, 2076, 2092, and $2132 \mathrm{~cm}^{-1}$ arise. The first three bands appear at similar (although slightly red-shifted) wavenumbers as the $v_{\mathrm{CN}}$ marker bands of the LT phase (see upper panel of Figure 8b). Comparison with the bleached $2153 \mathrm{~cm}^{-1}$ band reveals, however, much weaker absorption strengths of these transitions than for the LT phase. Note, that the IR transients also exhibit some residual absorptions for large pump-probe delays resulting from the residual molecules in the LT phase. The insert in Figure $8 \mathrm{~b}$ shows time dependent absorption changes recorded at 2076 (decay of the [Fe" ${ }^{\prime \prime} \mathrm{Co}{ }^{\prime \prime \prime} \mathrm{Fe}{ }^{\text {III }} \mathrm{Co}$ "I] intermediate) and $2153 \mathrm{~cm}^{-1}$ (recovery of the HT phase). Exponential fitting gives a time constant of $\tau_{1}=(2.1 \pm 0.5)$ ps for the lifetime of the [Fell Coll'Fell' $\left.\mathrm{Co}^{\prime \prime}\right]$ intermediate, which is in agreement with the UV/vis data shown in Figure 8a. Recovery of the $v_{\mathrm{CN}}=2153 \mathrm{~cm}^{-1}$ marker of the $\mathrm{HT}$ phase takes considerably longer, $\tau_{2}=(9.0 \pm 2.0) \mathrm{ps}$. We attribute this to vibrational cooling of the hot HT phase associated with the energy release of the $400 \mathrm{~nm}$ pump photon after IVCT and back electron transfer within a few ps. Overall, the IR spectra corroborate the assignment of a light-induced IVCT transition producing a [Fe" $\mathrm{Co}^{\prime \prime \prime} \mathrm{Fe} \mathrm{F}^{\text {III }} \mathrm{Co}$ "] intermediate which, according to its vibrational signature and short lifetime, has an electronic configuration different from $\mathrm{ET}_{1}$.

Dinuclear PBA 2. Figure 9 shows UV light-induced UV/vis (Figure 9a) and IR (Figure 9b) transient difference spectra of the dinuclear PBA 2 measured at room temperature. As noted before, 2 exists only in the HT phase. Comparison with Figure 8 reveals striking similarities in the shape of the spectra as well as the lifetime of the transient features, suggesting that PBA 2 undergoes the same light-driven IVCT dynamics as the HT phase of PBA 1. In fact, analysis of the time traces in the UV/Vis and IR spectra (inserts in Figures $9 \mathrm{a}$ and $9 \mathrm{~b}$ ) shows that the $\left[\mathrm{Fe}^{\mathrm{II}} \mathrm{Co} \mathrm{O}^{\mathrm{II}}\right]$ intermediates decay with time constants of $3.8 \pm 0.6$ and $3.7 \pm 0.4$ ps (2), respectively. The ground state bleach of the $v_{\mathrm{CN}}$ marker at $2143 \mathrm{~cm}^{-1}$ in case of 2 recovers considerably slower (7.8 $\pm 1.0 \mathrm{ps)} \mathrm{owing} \mathrm{to} \mathrm{vibrational} \mathrm{cooling} \mathrm{after} \mathrm{back} \mathrm{elec-}$ tron transfer.

The DFT calculated IR spectra discussed in section 2.3. turned out to be very helpful for identifying the electronic structure of the IVCT excited PBA 2 complex (see the stick spectra of Fig. 5b). The calculated spectrum of the ${ }^{3}$ [Fell'Is$\left.\mathrm{CO}{ }_{\mathrm{HS}}\right]$ state agrees well with the measured ground state FTIR spectrum of 2 . This suggests that the antiferromagnetic coupling between the metal centres is in fact weak such that ${ }^{3}\left[\mathrm{Fe}^{\mathrm{IIIS}}{ }_{\mathrm{LS}} \mathrm{CO}_{\mathrm{HS}}\right]$ and ${ }^{5}\left[\mathrm{Fe}^{\mathrm{III}}{ }_{\mathrm{LS}} \mathrm{CO}{ }_{\mathrm{HS}}\right]$ coexist and have very similar IR spectra. Most importantly, the calculated IR spectrum of the excited species ${ }^{5}\left[\mathrm{Fe}^{\mathrm{I}}{ }_{\mathrm{LS}} \mathrm{CO}{ }^{1{ }^{\prime \prime} \mathrm{HS}}\right.$ ] (black sticks in Figure $5 b$ ) exhibits a blue-shifted absorption in agreement with the transient IR spectrum of the light-induced IVCT product of 2 . Moreover, weaker absorptions of $v_{\mathrm{CN}}$
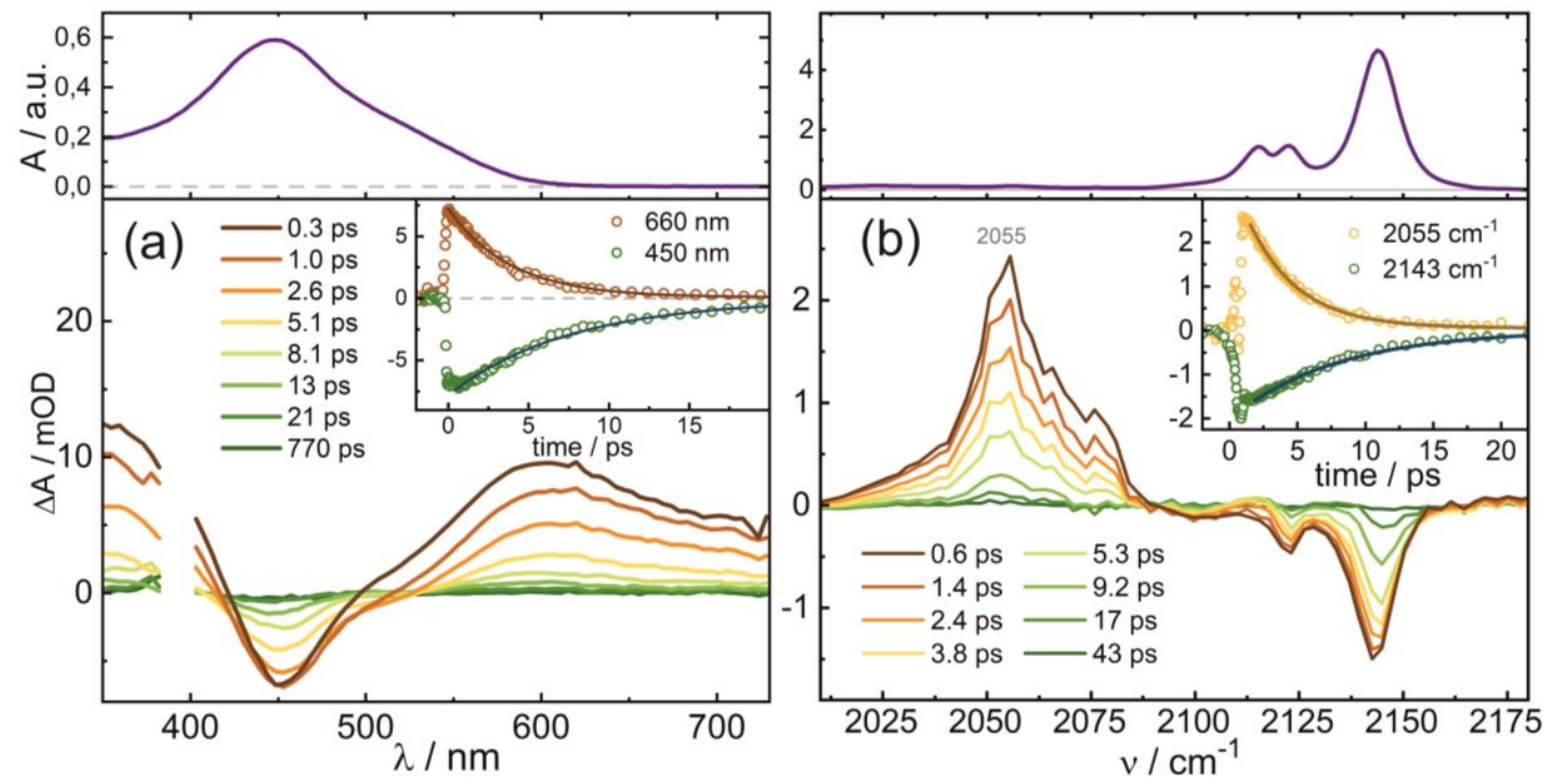

Figure 9. Pump pulse-induced UV/vis (a) and IR (b) transient difference spectra of PBA 2 at $+22^{\circ} \mathrm{C}$ in acetonitrile at pump-probe delays as indicated (pump wavelength: 775 and $800 \mathrm{~nm}$, respectively). The inserts show time traces for selected probe wavelengths along with exponential fits (solid lines). For comparison the upper panels present stationary UV/vis and FTIR spectrum of PBA 2, respectively. 
modes at 2127 and $2130 \mathrm{~cm}^{-1}$ overlap with those of the ground state and would partially compensate in a pumpprobe spectrum ground state bleach, as is in fact observed experimentally for the $2115 \mathrm{~cm}^{-1}$ mode in the IR transients of Figure $9 b$.

Thus, from the close agreement of the experimental stationary and transient IR spectra with the DFT calculations we conclude that the light-induced IVCT dynamics of PBA 2 involves population of a ${ }^{5}\left[\mathrm{Fe}^{\prime \prime}{ }_{\mathrm{LS}} \mathrm{CO}{ }^{\prime \prime \prime} \mathrm{HS}\right]$ state with a lifetime of 3.8 ps (see Scheme 3). Back-electron transfer produces a vibrationally hot ground state molecule that thermalizes on a timescale of $8 \mathrm{ps}$. From the remarkable similarities between Figures 8 and 9 we deduce an identical mechanism and dynamics operating for the photo-excited HT phase of tetranuclear PBA 1, in which only one of the [Fe-Co] edges is excited, and dinuclear PBA 2.

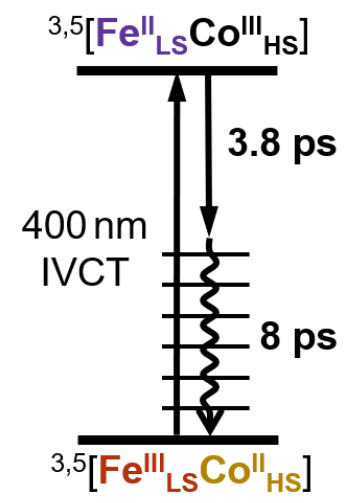

Scheme 3. Light-induced dynamics in PBA 2 and one [Fe-Co] pair of the HT phase of PBA 1. IVCT excitation produces a ${ }^{3,5}\left[\mathrm{Fe}^{\prime \prime}{ }_{\mathrm{LS}} \mathrm{CO} \mathrm{O}^{\prime \prime} \mathrm{HS}\right]$ state with a lifetime of $3.8 \mathrm{ps}$. The back-electron transfer leads to a vibrationally hot ground state cooling down on a timescale of 8 ps. Same color code as in Scheme 3.

\section{Conclusion}

This study has addressed the ultrafast dynamics following IVCT excitation of the known ${ }^{17}$ square-type molecular $\mathrm{Fe}_{2} \mathrm{CO}_{2}$ PBA 1 in both its high and low temperature phase, and of the dinuclear FeCo PBA 2, using pump-probe transient IR and UV/vis absorption spectroscopy of the complexes in MeCN solution. In that solvent PBA 1 undergoes thermal CTIST with $T_{1 / 2}=-11 \pm 4^{\circ} \mathrm{C}$ from the diamagnetic $\left[\left(\mathrm{Fe}^{\mathrm{II}} \mathrm{LS}_{2}\left(\mathrm{CO} \mathrm{CO}^{\mathrm{IIS}}\right)_{2}\right]\right.$ state (low temperature phase, $\mathrm{LT}$ ) to the the paramagnetic $\left[\left(\mathrm{Fe}^{\mathrm{III}} \mathrm{LS}_{2}\left(\mathrm{CO} \mathrm{HS}_{2}\right)_{2}\right]\right.$ state (high-temperature phase, HT). The new complex 2 has been shown by

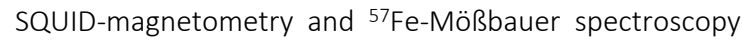
of solid material as well as UV/vis and IR spectroscopy of $\mathrm{MeCN}$ solutions to only exist in the [ $\mathrm{Fe}^{\mathrm{III}}{ }_{\mathrm{LS}} \mathrm{CO} \mathrm{O}_{\mathrm{HS}}$ ] state in the entire temperature range studied, and to thus represent a subunit of 1 in its HT phase. From the combination of femtosecond UV/vis and IR pump-probe experiments as well as computational analysis of relevant states a consistent picture of the light-induced dynamics upon metalto-metal electron transfer excitation of 1 and 2 could be developed. The results indicate that photo-induced oneelectron transfer of 1 is restricted to one edge of the
$\mathrm{Fe}_{2} \mathrm{CO}_{2}$ square and does not trigger a second (cooperative) charge transfer step at the opposite edge.

Complex 2 and the HT form of PBA 1 show similar photophysical behaviour after IVCT excitation, i.e. short excited state lifetimes (3.6 and 3.8 ps for 1 and 2, respectively) followed by back electron transfer and subsequent vibrational cooling of the hot ground state. In contrast, IVCT excitation of the LT phase of PBA 1 leads after fast spin crossover (400 fs) to a metastable tetranuclear [Fe" ${ }_{\text {LS Co }}{ }^{\prime \prime \prime}$ LSFe ${ }^{\prime \prime \prime}$ LS$\mathrm{CO}^{\prime \prime} \mathrm{HS}$ ] product with a lifetime $>1$ ns. These spectroscopic studies with femtosecond time resolution have delivered valuable insights into the elementary photophysical processes for the fascinating class of molecular Fe/Co PBAs.

\section{Experimental section}

\section{Materials and synthesis}

Manipulations involving air- and moisture-sensitive compounds were conducted under an atmosphere of dried (phosphorus pentoxide on solid support [Sicapent, Merck]) dinitrogen using standard Schlenk techniques. All used solvents and chemicals were purchased from common commercial sources or their synthesis is described below. $\mathrm{Co}(\mathrm{OTf})_{2} \cdot 6 \mathrm{H}_{2} \mathrm{O}, 42$ 2,6-Pyridinedicarboxaldehyde, ${ }^{43}$ $\mathrm{pz}_{4}{ }_{4} \mathrm{Lut}_{,}{ }^{41} \mathrm{Bu}_{4} \mathrm{~N}\left[\left(\mathrm{tp}{ }^{*}\right) \mathrm{Fe}(\mathrm{CN})_{3}\right]^{32}$ and $\left[\mathrm{CO}_{2} \mathrm{Fe}_{2}(\mathrm{CN})_{6}\left(\mathrm{tp}^{*}\right)_{2}\right.$

$\left.\left(4,4^{\prime} \text {-dtbbpy }\right)_{4}\right]\left(\mathrm{PF}_{6}\right)_{2} \cdot 2 \mathrm{MeOH}(1)^{17}$ were synthesized and characterized according to protocols described in literature.

Syntheses of $\left[\mathrm{COFe}(\mathrm{CN})_{3}\left(t p^{*}\right)\left(\mathrm{pz}^{*}{ }_{4} \mathrm{Lut}\right)\right] \mathrm{ClO}_{4} \cdot 2 \mathrm{MeOH}$ (2). $\mathrm{Co}\left(\mathrm{ClO}_{4}\right) \cdot 6 \mathrm{H}_{2} \mathrm{O}\left(45 \mathrm{mg}, 0.12 \mathrm{mmol}, 1\right.$ equiv.) and $\mathrm{pz}^{*}{ }_{4} \mathrm{Lut}$ (60 mg, $0.12 \mathrm{mmol}, 1$ equiv.) were dissolved in methanol $(20 \mathrm{~mL})$ to produce a pale yellow solution. $\mathrm{Bu}_{4} \mathrm{~N}\left[\left(\mathrm{tp}{ }^{*}\right) \mathrm{Fe}(\mathrm{CN})_{3}\right](84 \mathrm{mg}, 0.12 \mathrm{mmol}, 1$ equiv.) in methanol $(4 \mathrm{~mL})$ was added dropwise. The dark red mixture was stirred at room temperature for 2 hours and the reaction mixture was filtered. Dark red tabular crystals of $\mathbf{2}$ were obtained by slow diffusion of diethyl ether into the resulting solution (121 mg, $0.10 \mathrm{mmol}, 89 \%$ ). Anal. Calcd. for $\mathrm{C}_{47} \mathrm{H}_{63} \mathrm{BClCoFeN}_{18} \mathrm{O}_{6}: \mathrm{C}, 49.64 ; \mathrm{H}, 5.58 ; \mathrm{N}, 22.17 \%$. Found: C, 49.30; H, 5.50; N, 22.56\%. ESIMS (m/z): [M]+ calcd. for [CoFe $\left.(\mathrm{CN})_{3}\left(\mathrm{tp}^{*}\right)\left(\mathrm{pz}^{*}{ }_{4} \mathrm{Lut}\right)\right]^{+}:$973.36. Found: 973.36. ATR-IR $\left(\mathrm{cm}^{-1}\right): 2547\left(\mathrm{~V}_{\mathrm{BH}}\right), 2138\left(\mathrm{v}_{\mathrm{CN}}\right), 2120\left(\mathrm{v}_{\mathrm{CN}}\right)$.

\section{Instruments for steady state characterization}

Electrospray ionization (ESI) mass spectra were collected on a Bruker HCTultra instrument. Elemental analyses were carried out by the Analytical Department of the Institute of Inorganic Chemistry at the University of Göttingen, using an Elementar 4.1 vario EL 3 instrument. IR spectra of solid samples were measured with a Cary 630 FTIR spectrometer equipped with a DialPath and Diamond ATR accessory (Agilent) placed in a glovebox filled with $\mathrm{N}_{2}$. UV-vis spectra were recorded on an Agilent Cary 60 equipped with an Unisoku Cryostat (CoolSpek) and magnetic stirrer using quartz cuvettes with an attached tube and a screw cap with a septum. Temperature-dependent magnetic susceptibilities were measured using a Quantum-Design MPMS XL-5 SQUID magnetometer; details of the data 
analysis are given in the SI. ${ }^{57} \mathrm{Fe}$ Mössbauer data were collected with a ${ }^{57} \mathrm{Co}$ source embedded in a Rh matrix using an alternating constant acceleration Wissel Mössbauer spectrometer operated in the transmission mode and equipped with a Janis closed-cycle helium cryostat. Isomer shifts are given relative to iron metal at ambient temperature. Simulation of the experimental data was performed with the Mfit program. ${ }^{44}$

Crystal data and details of the X-ray diffraction data collections and analysis for 2 are provided in the Supporting Information. CCDC 2013399 contains the supplementary crystallographic data for this paper. These data can be obtained free of charge from The Cambridge Crystallographic Data Centre via http://www.ccdc.cam.ac.uk/data_request/cif.

\section{Pump-probe experiments}

Time dependent UV/Vis-pump-UV/Vis-probe spectra were recorded with a $1 \mathrm{kHz}$ Ti:sapphire oscillator/regenerative amplifier system. ${ }^{45}$ Briefly, for excitation pulses at the fundamental wavelength of $775 \mathrm{~nm}$ or its second harmonic at $388 \mathrm{~nm}$ were used. For probing a white light continuum was generated by focusing a small part of the 775 $\mathrm{nm}$ pulse into a $4 \mathrm{~mm} \mathrm{CaF}_{2}$ crystal. The continuum light was split into reference and probe pulses, and independently recorded with two diode array spectrometers.

UV/Vis-pump-IR-probe experiments were performed with a laser system described elsewhere. ${ }^{46} \mathrm{It}$ is based on a $1 \mathrm{kHz}$ Ti:sapphire oscillator/regenerative amplifier producing $100 \mathrm{fs}$ pulses at $800 \mathrm{~nm}$ with pulse energies of $0.75 \mathrm{~mJ}$. A small portion of these or its second harmonic at $400 \mathrm{~nm}$ were used as pump pulses. Tunable mid-infrared probe pulses were generated by difference frequency mixing of signal and idler pulses from an optical parametric amplifier (OPA) operated with half of the $800 \mathrm{~nm}$ regenerative amplifier energy. The IR pulses were split into a probe and a reference beam and after passing the sample directed to a polychromator equipped with a liquid-nitrogen cooled $\mathrm{HgCdTe}$ detector of $2 \times 32$ pixels.

In both setups the time delay between pump and probe pulses was adjusted with computer controlled translation stages. The relative plane of polarization of pump and probe pulses was set to $54.7^{\circ}$. Pump pulse energies entering the sample were about $400 \mathrm{~nJ}$ and focused to a diameter of $200 \mu \mathrm{m}$. . The overall time resolution was about $200 \mathrm{fs}$.

Temperature-depending UV/Vis and IR pump-probe measurements in a range of $-30^{\circ} \mathrm{C}$ to $+30^{\circ} \mathrm{C}$ were performed with a thermalized flow cell equipped with $\mathrm{CaF}_{2}$ windows of $1 \mathrm{~mm}$ thickness. The optical path length inside the flow cell was $0.6 \mathrm{~mm}$. The sample cell was thermalized with an external cooler (Julabo Laboratory $\mathrm{GmbH}$, Seelbach, type: $\mathrm{F} 40-\mathrm{HC}$ ).

\section{DFT calculations}

The structures of both PBAs were optimised with the def2SVP basis set. ${ }^{47}$ Three functionals were tested for a model of PBA 2: B3LYP, ${ }^{48}$ PBEO 49,50 and BP86.51,52 In all cases, dispersion corrections as proposed by Grimme and coworkers, ${ }^{53}$ applying a Becke-Johnson damping factor ${ }^{54}$ were included. In the case of PBA 1, only BP86-D3/def2-SVP calculations were carried out.

The structures were confirmed as minima by the absence of imaginary frequencies. In order to obtain the complexes under the different spin distributions (with the same total spin), fragment calculations were carried out and later combined for an initial SCF guess. The fragments were built placing the bridge on one of the disconnected metal sites. The reported wavenumbers were obtained under the harmonic approximation without any shifting or scaling. All calculations were carried out with the Gaussian16 program package. ${ }^{55}$

\section{ASSOCIATED CONTENT}

Supporting Information. The Supporting Information is available free of charge at https://pubs.acs.org.

Experimental and computational details, additional stationary and time-resolved spectra, global analysis of the pump-probe experiments, crystallographic data (PDF)

XYZ coordinates (in $\AA$ ) of the calculated structures (ZIP)

\section{AUTHOR INFORMATION}

\section{Corresponding Authors}

*E-mail: dschwar@gwdg.de

*E-mail: franc.meyer@chemie.uni-goettingen.de

*E-mail: ricardo.mata@chemie.uni-goettingen.de

\section{Funding Sources}

Deutsche Forschungsgemeinschaft (DFG, German Research Foundation) $217133147 /$ SFB 1073, projects B06 and $\mathrm{CO3}$.

\section{Notes}

The authors declare no competing financial interest.

\section{ACKNOWLEDGMENT}

Support by the University of Göttingen and the Max Planck Institute for Biophysical Chemistry is gratefully acknowledged.

\section{References}

(1) Bodenthin, Y.; Schwarz, G.; Kurth, D. G. SpinÜbergänge in Supramolekularen Strukturen. Für Speicherbausteine von Morgen? Chemie unserer Zeit 2008, 42 (4), 256-263.

(2) Létard, J.-F.; Guionneau, P.; Goux-Capes, L. Towards Spin Crossover Applications. In Spin Crossover in Transition Metal Compounds III; Gütlich, P., Goodwin, H. A., Eds.; Springer-Verlag: Berlin, 2004; pp 221-249.

(3) Hesselink, L.; Orlov, S. S.; Bashaw, M. C. 
Holographic Data Storage Systems. Proc. IEEE 2004, 92 (8), 1231-1280.

(4) Gamez, P.; Costa, J. S.; Quesada, M.; Aromí, G. Iron Spin-Crossover Compounds: From Fundamental Studies to Practical Applications. Dalton Trans. 2009, 7845-7853.

(5) Senthil Kumar, K.; Ruben, M. Emerging Trends in Spin Crossover (SCO) Based Functional Materials and Devices. Coord. Chem. Rev. 2017, 346, 176205.

(6) Sato, O.; Tao, J.; Zhang, Y.-Z. Control of Magnetic Properties through External Stimuli. Angew. Chem. Int. Ed. 2007, 46 (13), 2152-2187.

(7) Mathonière, C. Metal-to-Metal Electron Transfer: A Powerful Tool for the Design of Switchable Coordination Compounds. Eur. J. Inorg. Chem. 2018, 248-258.

(8) Meng, Y.-S.; Sato, O.; Liu, T. Manipulating Metalto-Metal Charge Transfer for Materials with Switchable Functionality. Angew. Chem. Int. Ed. 2018, 57 (38), 12216-12226.

(9) Aguilà, D.; Prado, Y.; Koumousi, E. S.; Mathonière, C.; Clérac, R. Switchable Fe/Co Prussian Blue Networks and Molecular Analogues. Chem. Soc. Rev. 2016, 45 (1), 203224.

(10) Shimamoto, N.; Ohkoshi, S.; Sato, O.; Hashimoto, K. Control of Charge-Transfer-Induced Spin Transition Temperature on Cobalt-Iron Prussian Blue Analogues. Inorg. Chem. 2002, 41 (4), 678684.

(11) Newton, G. N.; Nihei, M.; Oshio, H. CyanideBridged Molecular Squares - The Building Units of Prussian Blue. Eur. J. Inorg. Chem. 2011, 3031-3042.

(12) Sato, O.; Iyoda, T.; Fujishima, A.; Hashimoto, K. Photoinduced Magnetization of a Cobalt-Iron Cyanide. Science 1996, 272, 704-705.

(13) Berlinguette, C. P.; Dragulescu-Andrasi, A.; Sieber, A.; Galán-Mascarós, J. R.; Güdel, H.-U.; Achim, C.; Dunbar, K. R. A Charge-TransferInduced Spin Transition in the Discrete CyanideBridged Complex $\left\{\left[\mathrm{Co}(\text { Tmphen })_{2}\right]_{3}\left[\mathrm{Fe}(\mathrm{CN})_{6}\right]_{2}\right\}$. J. Am. Chem. Soc. 2004, 126 (20), 6222-6223.

(14) Berlinguette, C. P.; Dragulescu-Andrasi, A.; Sieber, A.; Güdel, H.-U.; Achim, C.; Dunbar, K. R. A Charge-Transfer-Induced Spin Transition in a Discrete Complex: The Role of Extrinsic Factors in Stabilizing Three Electronic Isomeric Forms of a Cyanide-Bridged Co/Fe Cluster. J. Am. Chem. Soc. 2005, 127 (18), 6766-6779.

(15) Li, D.; Clérac, R.; Roubeau, O.; Harté, E.; Mathonière, C.; Le Bris, R.; Holmes, S. M. Magnetic and Optical Bistability Driven by Thermally and Photoinduced Intramolecular Electron Transfer in a Molecular Cobalt-Iron Prussian Blue Analogue. J. Am. Chem. Soc. 2008, 130 (1), 252-258.

(16) Zhang, Y.; Li, D.; Clérac, R.; Kalisz, M.; Mathonière, C.; Holmes, S. M. Reversible Thermally and Photoinduced Electron Transfer in a Cyano-Bridged $\left\{\mathrm{Fe}_{2} \mathrm{CO}_{2}\right\}$ Square Complex. Angew. Chem. Int. Ed. 2010, 49 (22), 3752-3756. (17) Nihei, M.; Sekine, Y.; Suganami, N.; Nakazawa, K.; Nakao, A.; Nakao, H.; Murakami, Y.; Oshio, H.
Controlled Intramolecular Electron Transfers in Cyanide-Bridged Molecular Squares by Chemical Modifications and External Stimuli. J. Am. Chem. Soc. 2011, 133 (10), 3592-3600.

Mercurol, J.; Li, Y.; Pardo, E.; Risset, O.;

Seuleiman, M.; Rousselière, H.; Lescouëzec, R.; Julve, M. [Fe" $\left.{ }_{\mathrm{LS}} \mathrm{CO}{ }^{\prime \prime \prime}{ }_{\mathrm{LS}}\right]_{2} \Leftrightarrow\left[\mathrm{Fe}^{\prime \prime \prime \prime}{ }_{\mathrm{LS}} \mathrm{CO}{ }^{\mathrm{HS}}\right]_{2}$

Photoinduced Conversion in a Cyanide-Bridged Heterobimetallic Molecular Square. Chem. Commun. 2010, 46 (47), 8995-8997.

(19) Mitsumoto, K.; Oshiro, E.; Nishikawa, H.; Shiga, T.; Yamamura, Y.; Saito, K.; Oshio, H. CyanideBridged $\left[\mathrm{Fe}_{8} \mathrm{M}_{6}\right]$ Clusters Displaying SingleMolecule Magnetism ( $\mathrm{M}=\mathrm{Ni}$ ) and ElectronTransfer-Coupled Spin Transitions ( $\mathrm{M}=\mathrm{Co}$ ). Chem. Eur. J. 2011, 17 (35), 9612-9618.

(20) Gonzálvez, M. A.; Gallen, A.; Ferrer, M.; Martínez, M. Self-Assembly and Properties of a Discrete Water-Soluble Prussian Blue Analogue Fe"/Coll' Cube: Confinement of a Water Molecule in Aqueous Solution. Inorg. Chem. 2020, 59 (3), 1582-1587.

(21) Kamilya, S.; Ghosh, S.; Li, Y.; Dechambenoit, P.; Rouzières, M.; Lescouëzec, R.; Mehta, S.; Mondal, A. Two-Step Thermoinduced Metal-toMetal Electron Transfer and ON/OFF Photoswitching in a Molecular $\left[\mathrm{Fe}_{2} \mathrm{CO}_{2}\right]$ Square Complex. Inorg. Chem. 2020, 59 (17), 1187911888.

(22) Dong, D.-P.; Liu, T.; Kanegawa, S.; Kang, S.; Sato, O.; He, C.; Duan, C.-Y. Photoswitchable Dynamic Magnetic Relaxation in a Well-Isolated $\left\{\mathrm{Fe}_{2} \mathrm{Co}\right\}$ Double-Zigzag Chain. Angew. Chem. Int. Ed. 2012, 51 (21), 5119-5123.

(23) Liu, T.; Dong, D.-P.; Kanegawa, S.; Kang, S.; Sato, O.; Shiota, Y.; Yoshizawa, K.; Hayami, S.; Wu, S.; He, C.; Duan, C.-Y. Reversible Electron Transfer in a Linear $\left\{\mathrm{Fe}_{2} \mathrm{Co}\right\}$ Trinuclear Complex Induced by Thermal Treatment and Photoirraditaion. Angew. Chem. Int. Ed. 2012, 51 (18), 4367-4370. Mondal, A.; Li, Y.; Seuleiman, M.; Julve, M.; Toupet, L.; Buron-Le Cointe, M.; Lescouëzec, R. On/Off Photoswitching in a Cyanide-Bridged $\left\{\mathrm{Fe}_{2} \mathrm{CO}_{2}\right\}$ Magnetic Molecular Square. J. Am. Chem. Soc. 2013, 135 (5), 1653-1656.

(25) Cao, L.; Tao, J.; Gao, Q.; Liu, T.; Xia, Z.; Li, D. Selective on/off Switching at Room Temperature of a Magnetic Bistable $\left\{\mathrm{Fe}_{2} \mathrm{CO}_{2}\right\}$ Complex with Single Crystal-to-Single Crystal Transformation via Intramolecular Electron Transfer. Chem. Commun. 2014, 50 (14), 1665-1667.

(26) Sekine, Y.; Nihei, M.; Oshio, H. Abrupt Phase Transition Based on Electron-Transfer-Coupled Spin Transition in a Cyanide-Bridged $\left[\mathrm{CO}_{2} \mathrm{Fe}_{2}\right]$ Tetranuclear Complex. Chem. Lett. 2014, 43 (7), 1029-1030.

(27) De, S.; Jiménez, J.-R.; Li, Y.; Chamoreau, L.-M.; Flambard, A.; Journaux, Y.; Bousseksou, A.; Lescouëzec, R. One Synthesis: Two Redox States. Temperature-Oriented Crystallization of a Charge Transfer $\left\{\mathrm{Fe}_{2} \mathrm{CO}_{2}\right\}$ Square Complex in a $\left\{\mathrm{Fe}{ }^{\prime \prime}{ }_{\mathrm{LS}} \mathrm{CO}{ }^{\prime \prime \prime}{ }_{\mathrm{LS}}\right\}_{2}$ Diamagnetic or $\left\{\mathrm{Fe}{ }^{\mathrm{IIS}} \mathrm{LS} \mathrm{CO}{ }_{\mathrm{HS}}\right\}_{2}$ Paramagnetic State. RSC Adv. 2016, 6 (21), 17456-17459.

(28) Jiménez, J.-R.; Tricoire, M.; Garnier, D.; 
Chamoreau, L.-M.; von Bardeleben, J.; Journaux, Y.; Li, Y.; Lescouëzec, R. A New $\left\{\mathrm{Fe}_{4} \mathrm{CO}_{4}\right\}$ Soluble Switchable Nanomagnet Encapsulating $\mathrm{Cs}^{+}$: Enhancing the Stability and Redox Flexibility and Tuning the Photomagnetic Effect. Dalton Trans. 2017, 46 (44), 15549-15557.

(29) Nihei, M.; Shiroyanagi, K.; Kato, M.; Takayama, R.; Murakami, H.; Kera, Y.; Sekine, Y.; Oshio, H. Intramolecular Electron Transfers in a Series of $\left[\mathrm{CO}_{2} \mathrm{Fe}_{2}\right]$ Tetranuclear Complexes. Inorg. Chem. 2019, 58 (18), 11912-11919.

(30) Aguilà, D.; Prado, Y.; Koumousi, E. S.; Mathonière, C.; Clérac, R. Switchable Fe/Co Prussian Blue Networks and Molecular Analogues. Chem. Soc. Rev. 2016, 45 (1), 203224.

(31) Jeon, I.-R.; Calancea, S.; Panja, A.; Piñero Cruz, D M.; Koumousi, E. S.; Dechambenoit, P.; Coulon, C.; Wattiaux, A.; Rosa, P.; Mathonière, C.; Clérac, R. Spin Crossover or Intra-Molecular Electron Transfer in a Cyanido-Bridged Fe/Co Dinuclear Dumbbell: A Matter of State. Chem. Sci. 2013, 4 (6), 2463-2470.

(32) Koumousi, E. S.; Jeon, I.; Gao, Q.; Dechambenoit, P.; Woodruff, D. N.; Merzeau, P.; Buisson, L.; Jia, X.; Li, D.; Volatron, F.; Mathonière, C.; Clérac, R. Metal-to-Metal Electron Transfer in $\mathrm{Co} / \mathrm{Fe}$ Prussian Blue Molecular Analogues: The Ultimate Miniaturization. J. Am. Chem. Soc. 2014, 136 (44), 15461-15464.

(33) Bernhardt, P. V.; Martinez, M. The First Structurally Characterized Discrete Dinuclear $\mu$ Cyano Hexacyanoferrate Complex. Inorg. Chem. 1999, 38 (3), 424-425.

(34) Bernhardt, P. V.; Macpherson, B. P.; Martinez, M. Discrete Dinuclear Cyano-Bridged Complexes. Inorg. Chem. 2000, 39 (23), 5203-5208.

(35) Bernhardt, P. V.; Macpherson, B. P.; Martinez, $M$. The Influence of Cis/Trans Isomerism on the Physical Properties of a Cyano-Bridged Dinuclear Mixed Valence Complex. J. Chem. Soc. Dalton Trans. 2002, 1435-1441.

(36) Macpherson, B. P.; Bernhardt, P. V.; Hauser, A.; Pagès, S.; Vauthey, E. Time-Resolved Spectroscopy of the Metal-to-Metal Charge Transfer Excited State in Dinuclear CyanoBridged Mixed-Valence Complexes. Inorg. Chem. 2005, 44 (15), 5530-5536.

(37) Jafri, S. F.; Koumousi, E. S.; Arrio, M.-A.; Juhin, A.; Mitcov, D.; Rouzières, M.; Dechambenoit, P.; Li, D.; Otero, E.; Wilhelm, F.; Rogalev, A.; Joly, L.; Kappler, J.-P.; Cartier dit Moulin, C.; Mathonière, C.; Clérac, R.; Sainctavit, P. Atomic Scale Evidence of the Switching Mechanism in a Photomagnetic CoFe Dinuclear Prussian Blue Analogue. J. Am. Chem. Soc. 2019, 141 (8), 3470-3479.

(38) Daffé, N.; Jiménez, J.-R.; Studniarek, M.; Benchohra, A.; Arrio, M.-A.; Lescouëzec, R.; Dreiser, J. Direct Observation of Charge Transfer and Magnetism in $\mathrm{Fe}_{4} \mathrm{CO}_{4}$ Cyanide-Bridged Molecular Cubes. J. Phys. Chem. Lett. 2019, 10 (8), 1799-1804.

(39) Sekine, Y.; Nihei, M.; Kumai, R.; Nakao, H.; Murakami, Y.; Oshio, H. X-Ray-Induced Phase
Transitions by Selective Excitation of Heterometal lons in a Cyanide-Bridged Fe-Co Molecular Square. Chem. Commun. 2014, 50 (31), 4050-4052.

(40) Nihei, M.; Sekine, Y.; Suganami, N.; Oshio, H. Thermally Two-Stepped Spin Transitions Induced by Intramolecular Electron Transfers in a Cyanide-Bridged Molecular Square. Chem. Lett. 2010, 39 (9), 978-979.

(41) Morin, T. J.; Merkel, A.; Lindeman, S. V.; Gardinier, J. R. Breaking the Cycle: Impact of Sterically-Tailored Tetra(Pyrazolyl)Lutidines on the Self-Assembly of Silver(I) Complexes. Inorg. Chem. 2010, 49 (17), 7992-8002.

(42) Haynes, J. S.; Sams, J. R.; Thompson, R. C. Synthesis and Structural Studies of Iron(II) and Iron(III) Sulfonates. Can. J. Chem. 1981, 59 (4), 669-678.

(43) Hamon, F.; Largy, E.; Guédin-Beaurepaire, A.; Rouchon-Dagois, M.; Sidibe, A.; Monchaud, D.; Mergny, J.; Riou, J.; Nguyen, C.; Teulade-Fichou, M.-P. SI: An Acyclic Oligoheteroaryle That Discriminates Strongly between Diverse GQuadruplex Topologies. Angew. Chem. Int. Ed. 2011, 50 (37), 8745-8749.

(44) Bill, E. Mfit Program. Max-Planck Institute for Chemical Energy Conversion: Mülheim/Ruhr, Germany 2008.

(45) Walter, A.; Andresen, M.; Jakobs, S.; Schroeder, J.; Schwarzer, D. Primary Light-Induced Reaction Steps of Reversibly Photoswitchable Fluorescent Protein Padron0.9 Investigated by Femtosecond Spectroscopy. J. Phys. Chem. B 2015, 119 (16), 5136-5144.

(46) Vennekate, H. Photodecarbonylation of Diphenylcyclopropenone - a Direct Pathway to Electronically Excited Diphenylacetylene? Z. Phys. Chemie 2011, 225 (9-10), 1089-1104.

(47) Weigend, F.; Ahlrichs, R. Balanced Basis Sets of Split Valence, Triple Zeta Valence and Quadruple Zeta Valence Quality for $\mathrm{H}$ to $\mathrm{Rn}$ : Design and Assessment of Accuracy. Phys. Chem. Chem. Phys. 2005, 7 (18), 3297-3305.

(48) Becke, A. D. Density-functional Thermochemistry. III. The Role of Exact Exchange. J. Chem. Phys. 1993, 98 (7), 56485652.

(49) Adamo, C.; Barone, V. Toward Reliable Density Functional Methods without Adjustable Parameters: The PBEO Model. J. Chem. Phys. 1999, 110 (13), 6158-6170.

(50) Ernzerhof, M.; Scuseria, G. E. Assessment of the Perdew-Burke-Ernzerhof Exchange-Correlation Functional. J. Chem. Phys. 1999, 110 (11), 50295036.

(51) Perdew, J. P. Erratum: Density-Functional Approximation for the Correlation Energy of the Inhomogeneous Electron Gas. Phys. Rev. B 1986, 34 (10), 7406-7406.

(52) Becke, A. D. Density-Functional Exchange-Energy Approximation with Correct Asymptotic Behavior. Phys. Rev. A 1988, 38 (6), 3098-3100.

(53) Grimme, S.; Antony, J.; Ehrlich, S.; Krieg, H. A Consistent and Accurate Ab Initio Parametrization of Density Functional Dispersion 
Correction (DFT-D) for the 94 Elements H-Pu. J. Chem. Phys. 2010, 132 (15), 154104.

(54) Grimme, S.; Ehrlich, S.; Goerigk, L. Effect of the Damping Function in Dispersion Corrected Density Functional Theory. J. Comput. Chem. 2011, 32 (7), 1456-1465.

(55) Gaussian 16, Revision A.03, Frisch, M. J.; Trucks, G. W.; Schlegel, H. B.; Scuseria, G. E.; Robb, M. A.; Cheeseman, J. R.; Scalmani, G.; Barone, V.; Petersson, G. A.; Nakatsuji, H.; Li, X.; Caricato, M.; Marenich, A. V.; Bloino, J.; Janesko, B. G.; Gomperts, R.; Mennucci, B.; Hratchian, H. P.; Ortiz, J. V.; Izmaylov, A. F.; Sonnenberg, J. L.; Williams-Young, D.; Ding, F.; Lipparini, F.; Egidi, F.; Goings, J.; Peng, B.; Petrone, A.; Henderson, T.; Ranasinghe, D.; Zakrzewski, V. G.; Gao, J.; Rega, N.; Zheng, G.; Liang, W.; Hada, M.; Ehara, M.; Toyota, K.; Fukuda, R.; Hasegawa, J.; Ishida, M.; Nakajima, T.; Honda, Y.; Kitao, O.; Nakai, H.; Vreven, T.; Throssell, K.; Montgomery, J. A., Jr.; Peralta, J. E.; Ogliaro, F.; Bearpark, M. J.; Heyd, J. J.; Brothers, E. N.; Kudin, K. N.; Staroverov, V. N.; Keith, T. A.; Kobayashi, R.; Normand, J.;

Raghavachari, K.; Rendell, A. P.; Burant, J. C.; Iyengar, S. S.; Tomasi, J.; Cossi, M.; Millam, J. M.; Klene, M.; Adamo, C.; Cammi, R.; Ochterski, J. W.; Martin, R. L.; Morokuma, K.; Farkas, O.; Foresman, J. B.; Fox, D. J. Gaussian, Inc., Wallingford CT, 2016. 